\title{
Caring for Weak Ties - the Natural History Museum as a Place of Encounter Between Amateur and Professional Science
}

\author{
by Morgan Meyer \\ MINES ParisTech \\ Sociological Research Online, 15 (2) 9 \\ $<$ http://uww.socresonline.org.uk/15/2/9.html> \\ $10.5153 /$ sro. 2149
}

Received: 17 Aug 2009 Accepted: 5 May 2010 Published: 20 May 2010

\begin{abstract}
This article is concerned with a community of practitioners that does not hold together well: amateur scientists. It examines the interrelationships between amateurs and professionals in a museum of natural history and focuses, in particular, upon two 'community-making devices' through which they meet: an annual conference and a journal. I consider these devices as a place of encounter, or 'boundary encounter', between amateurs and professionals. These encounters provide for a combination of several practices practices of naming, assuring linguistic heterogeneity and thematic flexibility, exchanging knowledge and symbolic gifts - that enables the museum to keep the heterogeneous group of the amateurs somehow together. Since the connections between amateurs and professionals are not permanent, nor strong, but rather partial and fragile, they have therefore to be nurtured and cultivated with care. In fact, the museum and its professionals cannot continue to control - to use technical and 'cold' devices to discipline subjects - but have to care by fostering a 'warm' world of people. As I will show then, beyond their role as a place that brings together an epistemic collective, the encounters described in this paper also function as devices that nurture weak ties.
\end{abstract}

\section{Keywords: Amateur Scientists, Weak Ties, Community-Making Devices, Boundary Encounters, Museum of Natural History, Epistemic Collective}

\section{Introduction}

1.1 Imagine yourself sitting in a train. You might be talking to somebody, reading a book, or listening to some Led Zeppelin music. Every now and then, your thoughts are interrupted by the creaky voice coming from the speaker, announcing the name of the next station or - especially if you travel in the UK - informing you about the delay of the train. But then this. Suddenly the voice from the speaker addresses somebody in person. The voice tells a guy called Laurent to look out of the window now, because a badger was sighted some time ago right at the spot the train is just passing. People around you look surprised. So do you. A what? A badger? What is going on here?

1.2 This is a true story. This is what happened once on a train in Luxembourg (a very small country sandwiched between France, Germany and Belgium). From a speaker in a public transport system, where you would normally expect impersonal and repetitive communication, something quite personal and unique was uttered. A message was transmitted from the locomotive driver to only one passenger of the train. And the message was about something very specific: the location of an animal. Of course, the locomotive driver, called Guy, knew Laurent and had recognised him when the latter got on the train. Guy also knew that Laurent was interested in badgers. In fact, both knew each other through the Luxembourg Museum of Natural History, as both are scientific collaborators of this institution. So, funny as he is, Guy told Laurent and all the other passengers of the train that he had seen a badger at the spot the train was just passing. $A$ piece of knowledge was exchanged on a train, through a speaker. A quite unusual incident.

1.3 The same locomotive driver happened to surprise me too, one day when I was far away from Luxembourg. I was looking at a photographic exhibition in Oslo, Norway with a couple of friends of mine and we chatted in Luxembourgish. Suddenly we were approached by a man who started talking in Luxembourgish with us. The stranger from Luxembourg asked us what we were doing in Oslo and we explained our reasons for being there. The person who was talking to us, Guy, was taking part in the 7th International Mycological Congress. The congress was taking place at the University of Oslo and Guy was presenting a poster. 
1.4 A locomotive driver who takes part in an international congress on mushrooms and - as I found out later - is even paid the travel costs to go there? Another strange story, it seems. You would not necessarily expect a locomotive driver to be knowledgeable in natural history. More so, at an international congress on mycology you would rather suppose professional scientists dealing with mushrooms to be present. Yet, there are some people who challenge these sometimes taken-for-granted realities. People like Guy, and many of the other 200 scientific collaborators of the Luxembourg Museum of Natural History (hereafter the Museum with a capital M), seem somehow to belong to two worlds, that of the professional scientist and that of the amateur or the naturalist. Among the scientific collaborators of the Museum there are all sorts of people: a bank employee interested in astrophysics and collaborating with NASA, a school teacher fascinated with beetles, a young student interested in and publishing about fossils. In short, many of the Museum's collaborators are people whose profession or day job does not bear a direct link with their active scientific interests. However, they seem to be doing similar things than we expect of professional scientists: they publish articles, do fieldwork, give talks, present posters at conferences. Even though they are usually not members of professional associations or scientific communities, they still produce knowledge that is considered as science. This raises a number of questions: Where do amateurs and professionals meet? What do these places look like? What things, other than scientific knowledge, are exchanged when they meet? (How) does a museum try to create a homogeneous and disciplined place to bring amateurs and professionals together?

1.5 The boundary between the activities of amateurs and professionals is not clear-cut. Rather than being produced only by professional researchers, science in the Museum originates from a close cooperation between specialised people and laypersons - a model termed 'co-production of knowledge' by Callon (1998a, see also Callon et al. 2001). As a consequence, amateurs come to belong to the world of the professional too. Thus, instead of demarcating science from non-science, the co-production of scientific knowledge model includes the activities of lay people who are enrolled in scientific production and who are usually seen as marginal to 'proper' science. Such a focus on the involvement of amateurs in science can be useful to explore scientific practice and communities of scientists. It has been argued that studying science amateurs can be especially interesting as their serious leisure informs us about work itself (Stebbins 2004:49) and that we better learn about 'science' through contrasts to 'non-science' (Gieryn 1983:791). It can thus be revealing to study scientific communities by focussing on the edges of these communities and by examining the co-production of knowledge by amateurs and professionals. Amateurs are sociologically interesting since they are a good example of people who are only loosely tied to communities, of people who form an 'epistemic collective' rather than an 'epistemic community'. As such they escape - but also make manifest - the governing and coordinating mechanisms of science. To study a group of people that is only loosely held together is a good entry point to further explore identities, relationships, and the way disciplinary techniques do and do not work.

1.6 Scientists move in communities of practice (Star 1991:41). That is, they move within communities that very often don't have clear boundaries. For Lave and Wenger (1991:98), the term community does not imply 'necessarily co-presence, a well-defined, identifiable group, or socially visible boundaries. It does imply participation in an activity system about which participants share understandings [...] A community of practice is a set of relations among persons, activity, and world, over time and in relation with other tangential and overlapping communities of practice'. The boundaries of communities of practice are usually rather fluid (Wenger 2000:232) and participants may disengage and are prone to detachability (Lave and Wenger 1991:19). Amateurs, in particular, often find themselves partially connected to scientific communities (see Strathern 1991, Meyer 2008).

1.7 In this article, I will focus upon two 'community-making devices' through which amateurs and professional meet: a conference and a journal. Community-making devices, it has been argued, are devices that 'help to create a sense of a global collective of people and practices' - be they associations, events, conferences, or journals, they are 'markers and makers of community' (Molyneux-Hodgson and Meyer 2009:143). I will be considering these devices as a place of encounter - or 'boundary encounter' to use Wenger's term (1998:112) - between amateurs and professionals in which various issues come to the fore: practices of naming, linguistic heterogeneity and thematic flexibility, as well as various kinds of knowledge and symbolic gift-exchange. It is, amongst others, through these devices that the Museum keeps the amateurs somehow together and nurtures the partial and fragile connections that link them to the Museum. As we will see, the Museum cannot control and discipline people, by using 'cold' devices, but has to care by fostering a 'warm' world of people.

1.8 On the one hand, the Museum, as any museum, is a space with clear walls. It is a legal, official and architectural space for collections of natural history. And, it produces knowledge by drawing things together: by concentrating artefacts, knowledge and people in a singular place. A museum of natural history reveals two inter-linked dreams: the dreams of scientists to know nature, to put names on plants and animals and order them in space, and, the panoptical dream to better govern the natural empire by 
cataloguing it completely through 'biodiversity panopticons' (Bowker 2000:645). Species are classified, regions are defined, knowledge is fragmented, all in order to be able to be accumulated at a centre. The dream is, then, that of all the nonhuman inhabitants of Luxembourg becoming visible in detail, at all times, from a central point (Meyer 2009). For the people who work in the Museum, it is a place where careers are regulated, collective work is scheduled and people are remunerated. The Museum is a place closed off by walls, by rules - it is a framed and controlled place. Stated differently, the museum is a disciplined and enclosed space (see Foucault 1979:141).

1.9 However, to fully realise its 'panoptical dream', the Museum would have to lock its collaborators into clear positions, discipline them, prescribe their gestures and practices, regulate their times, etc. (see Foucault 1979). But because most of them are amateurs and volunteers, the collaborators cannot (easily) be disciplined. This lack of control is especially noteworthy at the present time, a time where many debates focus on the governance of science; where research funds and funding councils have developed an increasing number of tools to prioritise, assess, police and direct research activities; where on a European level, much efforts are being made to harmonise and coordinate research efforts across nations, cultures, and disciplines; where there is much talk about creating a competitive knowledge economy; where states have developed increasingly fine-tuned policies to formalise, professionalize and control science. ${ }^{[1]}$ Amateurs' knowledge production takes place in a somewhat exotic and protected niche within these current efforts to prescribe, to coordinate and to impose rather rigid frames.

1.10 In the next section I discuss the relationship between amateurs and professionals from a historical point of view, this, in order to provide some more background for the subsequent sections. Thereafter I turn to the specific case of the collaborators of the Luxembourg Museum of Natural History and examine how they have been described as a heterogeneous group. Then I will explore two specific encounters between the Museum staff and the collaborators (an annual meeting and a journal). The research findings that I present stem from a qualitative case-study conducted at the Museum (Meyer 2006) and empirical data are drawn from participant observation and semi-structured qualitative interviews with scientific collaborators (C) and staff members (S) of the Museum. (Note that no explicit theory guided data collection and that the paper is based on a rather exploratory project that tried to leave as much room as possible for new ideas.)

\section{The relationships between amateurs and professionals from a historical point of view}

2.1 In order to better understand contemporary relations between amateurs and professionals, we have to move back in time a couple of centuries to trace how these relations have emerged, evolved, and changed. For Findlen (1994:10) a common problem in the history of science is the neat division between 'scientists' and 'amateurs'. She argues that professional and amateur systems of knowledge could and did co-exist in the 16th and 17th centuries. It is commonly held that the emergence of amateurs paralleled that of professionals: 'As professionalization occurs, those who retain their serious, albeit part-time, commitment to the activity are gradually transformed into amateurs' (Stebbins 1992:14-5).

2.2 The history of most sciences (and their professionalization) is that of an extreme confinement that sets laboratories and instruments out of reach of the amateur and the layperson (Callon et al. 2001:65). The strength of the laboratory - its precision of measurement and the elimination of interferences - has made it necessary for experiments to be done in a private and confined space (Callon et al. 2001:72). Today's laboratory is a spatially and socially organised form that can be traced back to the 'house of the experiment' (Shapin 1988). To have access to this space, philosophers had to be humble, noble, honest and trustworthy (Shapin and Schaffer 1985:130-1). In fact, trust was an important aspect in experimental philosophy in 17th century England and crucial for demarcating the community of philosophers: 'The distribution of trust is therefore coextensive with the community, and its boundaries are the community's boundaries' (Shapin 1994:36). What counted as truth and science depended on who spoke on behalf of nature and whether he was respected as a gentleman. Mainly three technologies were used to produce knowledge: a material technology (the construction of machines), a literary technology (the dissemination of results to non-witnesses) and a social technology (the conventions to use) (Shapin and Schaffer 1985:2579).

2.3 Concomitant with professionalization, amateurs were constructing a new identity through 'amateurization' in the 19th century (Alberti 2001:117, 132-6, see also Taylor 1995:504). Through this evolution a semantic switch of the term 'amateur' has occurred (see Stebbins 1992:10, Drouin and Bensaude-Vincent 1996:417-8). 'Amateur' etymologically comes from amatore, the one who loves, and denotes a devotee who takes an interest in a particular activity out of 'love' (see Stebbins 1977). But whereas up to the 19th century amateur meant the one who loves, there was a shift of the term to signify the one who does it in spare time (Alberti 2001:116).

2.4 Towards the end of the 19th century, the contrast between 'amateur' and 'professional' was reinforced (Drouin and Bensaude-Vincent 1996:418-9). Mathematization and the growing complexity of practical 
laboratory work were two key factors that led to the disappearance of the amateur from certain sciences (O'Connor and Meadows 1976:78). '[P]rofessionalization, involving as it did increasing stress on credentials, research apprenticeship, and sophisticated instrumentation, pushed even the wealthy amateur toward the sidelines' (Lankford 1981:289).

2.5 In natural history there have been important shifts in the nature of knowledge practices which affected amateurs. There was a transition from observational and comparative approaches (for classification and morphology) to include experimental, manipulative and quantitative techniques (Star and Griesemer 1989:394). In Pickstone's (2000) words, natural history has been supplemented by other 'ways of knowing'. Throughout these shifts, professional scientists have sought to demarcate themselves from amateurs. Historically, the development of the research natural history museum was an important stage in the professionalization of natural history work, and an example of the changing relationship between amateurs and professionals (Star and Griesemer 1989:391). In America during the first decades of the 20th century, professional biologists sought international credibility by distinguishing themselves from amateurs, establishing advanced degrees as credentials, and establishing specialised journals for publication (Star and Griesemer 1989:393). There were attempts to 'expulse' amateur science from professional science - to put it in Gieryn's terms. The creation of the museum was in effect a means for professional zoologists to claim greater scientific authority for their work by distancing it from activities of amateurs and conservationists (Gieryn 1995:415). It has been argued that, in general, professions seek to establish their authority and autonomy through the construction of various boundaries around themselves (Fournier 1999:282).

2.6 By the end of the Victorian era, then, 'the sciences were rapidly dividing into a multitude of specialized domains, each requiring rigorous academic training and access to expensive and complex research facilities. The process separated amateurs and professionals [...] Yet the amateur was not driven from the field' (Lankford 1981:277).

2.7 Despite the increase of laboratory science, amateurs continued to collaborate with laboratory-based biologists (Alberti 2001). In natural history especially, amateurs and professionals developed a fruitful and continuing relationship (Lankford 1981:276) - and their collecting practices were united (Asma 2001:113). In today's museums too, the increasing professionalization has not entirely excluded non-professionals: 'At the same time that [...] staff hiring [is] more routinely based on certification, museums are turning to nonprofessional, noncertified, indigenous sources' (Hein 2000:40).

2.8 In natural history museums amateurs were and still are a vital element. They ensure the museum's scientific success, as providers of specimens and information that scientists were and are too few to gather by themselves (Gieryn 1995:415). Compared to laboratory science, knowledge production in the natural history museum differs in terms of the prevalence of fieldwork and the kinds of tools being used. Historically, the field was not considered to be a very scientific space. The act of analysing data collected by others in the field was not problematic and was admissible for subsequent scientific investigation. More so, natural history fieldwork was not considered to be a gentlemanly activity, but unpleasant, inglorious, dirty, and dangerous work (Kuklick 1997:53). However, accounts were not accepted as authentic until gentlemen-scientists attested to their veracity (Kuklick 1997:57). As a more decentred and field-based way of producing knowledge, natural history still bares the trace of this historical entanglement between amateurs and professionals, between the laboratory and the field, between inside and outside. The second key difference between laboratory science and natural history is the kind of tools being used. In fact, natural history fieldwork requires only a few tools and most of these tools are cheap, handy, rather ubiquitous, and easily available (Meyer 2008). The mobility and transportability of scientific tools and material is one factor helping to explain why some scientific fields are more open to amateurs than others:

In such fields scientific practice is related to 'lighter' materialities. A field guide or a magnifying glass can easily be transported [...] The field or the home can be turned into a scientific space without much money, degrees, and technical equipment. Amateurs can quite easily co-produce scientific knowledge if, on the one hand, the spaces in which they do so are 'light' and 'movable' - if, in a sense, they themselves can move these spaces around and, on the other hand, if the materialities and sociabilities of the inside of the Museum can be transported outside without too much cost and loss (Meyer 2008:47-48).

2.9 Compared to professional scientists, amateurs enjoy more freedom (Lankford 1981:298). This freedom means, amongst other things, that amateurs are hard to keep under control (Stebbins 1992:55-7, 2004:1003). ${ }^{[2]}$ This uncontrollability is a feature that runs throughout the history of amateurs in natural history. Drouin and Bensuade-Vincent (1996:419) suggest that in the early 19th century,

the difficulty was not to get the cultivators of natural history to work, since they volunteered and worked eagerly. Nor was it to gather reports, information and collections from them, since 
many local natural history societies included both volunteers of various degrees of training and a few paid naturalists, and were able to provide such materials. The main problem was that the cultivators of natural history formed an undisciplined crowd which the professionals would like to keep under their control.

2.10 Still nowadays, for museum professionals to collaborate with amateurs means to manage an ambiguous situation. As volunteers, amateurs are able to move more or less freely within the museum's institutionalised science; as scientists they tend to be controlled and fixed into a rigid system. However, this does not mean that this situation is temporary, that in the long run amateurs will become either full members or non-members of scientific communities of practice. Instead, amateurs are on the 'periphery of practice', 'a region that is neither fully inside, nor fully outside and surrounds the practice with a degree of permeability' (Wenger 1998:117).

2.11 The term peripherality suggests that 'there are multiple, varied, more- or less-engaged and - inclusive ways of being located in the fields of participation defined by a community' (Lave and Wenger 1991:35-6).

'Peripheries [...] refer to continuities, to areas of overlap and connections, to windows and meeting places' (Wenger 1998:120). Thus, being a member or 'belonging' to a scientific community is not an all or nothing relationship.

2.12 In order to conceptualise the peripheral status of amateurs and to account for the fact that they are somehow linked to professional science, a number of concepts have been developed, such as 'serious leisure' (Stebbins 1992), 'lay experts' (Epstein 1995), and 'partial scientists' (Meyer 2005). For Ellis and Waterton (2004), who talk about 'amateur experts', the amateur and the professional worlds are 'two separate yet interconnected, antagonistic, yet mutually respectful worlds'.

\section{A 'wild bunch': the scientific collaborators of the Luxembourg Museum of Natural History}

3.1 Let me now focus on the scientific collaborators of the Museum as one example of such amateur experts who are situated at the periphery of a scientific institution. The status of scientific collaborator emerged in parallel to the creation of the Museum's Centre of Scientific Research in 1982. Scientific collaborators are associated to the scientific research programmes carried out by the centre and they work on a voluntary basis. Their number has increased ever since: from 41 in 1983 to 139 in 1991 to 182 in 2004.

3.2 The title of scientific collaborator is conferred, after proposal of a conservator, by the Luxembourg Minister of Cultural Affairs. After a person is nominated scientific collaborator, his or her name is published in the official legal journal of Luxembourg, the Mémorial. There, two lists appear: one with newly added names and one with those collaborators whose mandate has been renewed. In these two lists the collaborators' names are written down in alphabetical order and next to each name their address appears along with the scientific section of the Museum they are affiliated to. Apart from these lists, their names also appear individually in a document every collaborator receives - collaborators are given a 'legitimisation card' that authorises them to use in the scope of their research roads and ways prohibited to the public.

3.3 The above techniques of writing the collaborators into documents are standardised and centralised. On a technical level, then, 'the scientific collaborator' is a simple and coherent construct; a person which exists in a legal text, owns a legitimisation card, and is named in alphabetical lists. This is achieved through processes of inscription - the production of durable and mobile traces which can be transported and accumulated and compared at a centre (Latour 1987). By writing the names of the collaborators onto a surface, by coding them into diverse documents, the Museum creates a textual space of similarities, of commonalities.

3.4 Yet, centralising the collaborators, their data, and their interests within the Museum is difficult for many reasons. First, their nationality and country of residence are diverse. Besides a great majority of Luxembourgish nationals, there are also non-natives, mainly French, Belgian and German nationals. Most live in Luxembourg, whereas the others live in the neighbouring countries. Second, as already alluded to, the professional activity of the collaborators varies. Amongst them there are persons affiliated to other scientific institutions, teachers, students, retired persons, people who work in domains which have nothing to do with science (bankers, engine drivers...), etc. Third, they do not necessarily collaborate with the Museum to the same degree. As the former Museum director explained, there are some Pabeierläichen (literal translation: paper corpses), that is, people who have collaborated to only one project and who exist, for the Museum, only on paper. At the other extreme, there are some very active, productive and internationally renowned collaborators. These three differences - country of residence/nationality, professional activity, and degree of activity - turn the collaborators into a very heterogeneous group.

3.5 Moreover, the collaborators' research subjects are very diverse, ranging from mushrooms to mammals to fossils. The governmental counsellor for research at the Ministry of Culture, Higher Education and 
The scientific collaborators [...] work in very heterogeneous fields. There is a dispersion on very many domains, too many perhaps, in my eyes. And it would have been useful to the whole thing if one could concentrate on a few domains. [...] One person works on mosses, another on frogs, a third one works on, I don't know, on a specific bird species, and a fourth one on a wood disease. Everything, every research project has its own importance. But it doesn't attain an impact because there is no work in cooperation. Or then, why not tackle works in a multidisciplinary way, [...] work together, towards a common goal? It seems to me $[\ldots]$ that it is relatively mosaic-like, out of separate pieces. And it is difficult to bring those pieces together (extract from interview).

3.6 The alleged difficulty to bring these 'mosaic-like' pieces together reveals that the different scientific interests of the collaborators do not seem to add up. To counter-balance this diversity, the interviewee articulated different means: 'concentrating', 'cooperation', working towards 'a common goal', in other words, aligning and connecting the collaborators' practices.

3.7 The collaborators do not really form a homogeneous group. It seems to be more of a 'community without unity' (Corlett 1989). Staff members described the collaborators as follows: 'it is a multicoloured heap' (S1), 'as there are all kinds [of collaborators], in fact, it is thus difficult to put all of them into the same box' (S2). As one staff member put it: 'it is not a group, it is [...] a list of people' (S3). He further argued: '[The scientific collaborators] are something like a wild bunch. So it isn't a group, where one would say that it stands together and heads towards the same goal. Goals are individual. And we then have to look to what extent we can bring that in resonance with what we really want'.

3.8 Bringing individualistic goals in resonance with institutional goals is an ambition that runs through the development of natural history. Already in the early 19th century, those who practised natural history were, to the eyes of professionals, a rather 'undisciplined crowd' difficult to keep under control (Drouin and Bensuade-Vincent 1996:419).

3.9 In the Museum, it is difficult to keep amateurs under control since the connection between the Museum and its collaborators is a weak one, a connection described in the following ways: 'It is a terribly loose collaboration' (former museum director); 'It isn't a relation that is permanently there. It is basically a link that is made like a telephone connection. And when it is finished, I hang up. Then I'm alone again. A more permanent contact is somewhere missing. A stronger bond is missing' (C1).

\section{Two boundary encounters}

4.1 Let me now turn to two 'boundary encounters' (Wenger 1998:112) between the Museum staff and the collaborators: the annual meeting of the collaborators and the Museum's journal. ${ }^{[3]}$

\section{The annual meetings of the collaborators}

4.2 Each year in March, the scientific collaborators and the staff members of the Museum get together for a one-day conference. The first meeting of this kind took place in 1983, one year after the creation of the Museum's Centre of Scientific Research.

4.3 Over the years, the conference has changed in a number of ways. According to its current organiser, in the early days there were many talks on what he called 'the flowers in the prairie' (S4). Talks used to be rather descriptive, a naturalist's account on species present in one particular region. But talks seem to have become increasingly analytic and scientific. In 2005 a scientific committee has been set up to select speakers, a procedure that wasn't common before. The conference has also changed in terms of more mundane things - the introduction of badges for the participants in 2004, the increased use of computers for presentations - which point towards the same trend: a (proto)professionalization of the conference.

4.4 I attended two of these annual meetings: the one in 2004 and the one in 2005. I now examine the 2004 meeting in more detail. The 2004 conference started at $2 \mathrm{pm}$. The first two introductory speeches were given by the Museum director and the governmental counsellor for research matters.

4.5 Both the speech of the Museum director and that of the governmental counsellor were in some respects very similar. First of all, both were dressed very formally - in suit and tie - while most of the conference participants were not. Both thanked the collaborators a couple of times during their speeches. The two talks, I would argue, set a certain frame: this was to be an event about science; it was an official, important and relatively formal event; and it was strongly related to Luxembourg. After these introductory talks, the collaborators hit the stage. There were 11 talks: six were held in Luxembourgish, three in French 
and two in German. A lot of the talks dealt with palaeontology but all in all the subjects covered a very broad range: fossils, meteorites, trees, mussels, climate, etc. ${ }^{[4]}$

4.6 The meeting is an institutionalised space where findings are communicated and knowledge exchanged. In general, conferences are one of the traditional channels - with journals - for scientific dissemination of knowledge (Lamb and Davidson 2005). They provide forums where findings become publicly available information (Garvey and Griffith 1972). Yet, the annual meeting of the collaborators is not only a place where findings are communicated in a linear and unidirectional way, where an active speaker transmits a message to a passive audience (see Hooper-Greenhill 2000, Keith 1997). Rather, the conference is marked by a twoway communication process, a place where calls are issued, questions asked, information sought, ideas suggested, responses and criticisms given. The annual meeting is a place for conversation, for dialogue.

4.7 At academic conferences speakers are usually selected according to the content of their proposed talk. Yet, for the annual meeting of the collaborators, talks are selected according to the person who gives the talk rather the content or the topic of the talk. In fact, not everybody who submits an abstract is selected. The organiser of the conference explained: 'It is a bit like this, that there also should be an alternation [...] If there are too many demands, I think you also have to take those who haven't been there before' (S4).

4.8 Those collaborators who gave a talk at a recent meeting are sometimes rejected in favour of those who haven't done so. The annual meeting thus reveals a 'temporal turn taking' (Lewis and Weigart 1990:81) between the collaborators. This temporal turn taking is quite rare for communicating science. While a similar practice has been observed in communities of high energy physics, where 'taking turns' is one criterion for choosing speakers (Knorr-Cetina 1999:169), in most scientific communities this is not common practice.

4.9 Apart from this turn taking, the meeting is peculiar in other ways as well. It is an inherently heterogeneous forum. At the 2004 event three different languages were used (German, French and Luxembourgish), while at the 2005 event some of the speakers also talked in English. In fact, the collaborators are free to choose in which language to present their findings. According to the organiser of the conference:

We leave the collaborators free choice on this matter. Most participants are Luxembourg nationals, the majority of the presentations are and were held in Luxembourgish. A French, English or German speaker will of course speak his own language (a feature which is increasing). There have been internal discussions in the Museum to hold the events in one language only, but this hasn't succeeded yet [...] Were it to be a congress where only professional researchers would present their results, it would probably have to be held in English. But this is not the case. During this meeting, people who do not speak other languages well enough should also have a voice (S4).

4.10 Apart from this linguistic diversity, the event was heterogeneous in other ways. First, the professional background of the conference participants was diverse. For the organiser of the conference: 'The whole thing reflects a bit what the corpus of the collaborators finally is. It is extremely heterogeneous. There are people who work professionally, there are people who do this as a hobby, and there are also people amongst them who have no scientific education' (S4).

4.11 Second, the subjects and the styles of the presentations were diverse. Collaborators covered a large range of topics related to natural history, and they used different styles to present their findings. In sum, the conference is marked by heterogeneity in terms of languages used and participants' backgrounds, interests and styles of presentations. As these are amalgamated at one single event, they resemble what has been called 'hybrid forums'. For Callon and Rip (1992:147-153) 'hybrid forums' are characterised by the multiplicity and diversity of actors that interact; they are hybrid since the actors, the problems they formulate and the resources they mobilise are heterogeneous.

4.12 After the talks, meetings do not end straightaway but are usually followed by a wine reception and a dinner in a restaurant. At both the 2004 and 2005 events quite luxurious dinners were served which the Museum paid for, including three courses, wine and coffee. 'This is where I like collaborating' one collaborator amusingly commented about the annual dinner (C2). Thus, apart from being forums for the exchange of knowledge, the annual meetings are an occasion for the Museum to show its appreciation by offering the collaborators something in return, a kind of gift (see Mauss 1990). The importance of gift making in science has been examined by Hagstrom (1982) who argued that the link that unites scientists to their community is based upon transactions; that it consists of an exchange of information against credit. This gift economy helps to organise relationships between people in a certain way in that it implies a recognition of the status of the donor and the existence of reciprocal rights, which might be to return a gift or to show appropriate sentiments of gratitude (Hagstrom 1982:21). Not only have the collaborators no conference fee 
to pay, they are also offered a dinner and free issues of the Museum's journal. But gift giving does not only consist of exchanging objects: in virtual communities, for example, it is through acknowledgement that the giver can receive a certain amount of fame and respect (Bergquist and Ljungberg 2001:313). In a similar way, the annual meetings are places were the Museum shows its recognition towards the collaborators by thanking them in official speeches. What might seem a mundane and banal thing to say, 'thank you', is endowed with much significance. To sum up, then, at the meetings gift exchange takes many forms: verbal (showing gratitude by saying 'thank you'), organisational (providing a pleasant forum for exchange) and culinary (offering a dinner, wine, etc.). Gift exchange is a heterogeneous practice.

\section{The Museum's journal}

4.13 Apart from meeting in physical encounters, the Museum staff and the collaborators also meet through the Museum's journal. Since 1981, the Museum issues a journal where both staff members and collaborators can publish their findings. While some staff members have published their works in this journal it is, however, mainly intended for publications from the collaborators. The journal was initially called Travaux Scientifiques du Musée National d'Histoire Naturelle (Scientific works of the National Museum of Natural History). The length of the monographs varies considerably. In fact, except for a technical limit there is no set page limit and contributions can be between 20 and 200 pages long.

4.14 Most of the issues of the journal are single-authored monographs. But we must shift our focus from authorship to contributorship (Cronin 2001) to see the many helping hands and thoughts that go into a single-authored text. Especially the acknowledgment sections reveal the collaborative nature of the pieces: people are thanked for the data they have sent to the author(s), for providing them with information about the location of some species, for proofreading, etc. In general, acknowledgments sections repay intellectual debts by giving credit to contributors and, by reconciling individual achievement with collective ownership of knowledge, they reveal the dialogic and interpersonal nature of science (Giannoni 2002:8-9). In other words, these sections show to what extent texts are co-produced by more than one person rather than produced by a single author.

4.15 In 2002 the journal was given a 'new face': it was renamed Ferrantia, the format was enlarged and the articles are now in a two-column layout to create a 'more dynamic look' (as explained on the Museum web site). An editorial board consisting of five staff members was set up whereas before only one staff member was in charge of editing the journal. At the same time, instructions to authors have been established. In these instructions we can read:

FERRANTIA is a series of monographic works [...] dealing with life and earth sciences, preferably related in some way or other to the Grand-Duchy of Luxembourg. It publishes original results of botanical, zoological, ecological, geological, mineralogical, palaeontological, geophysical and astrophysical research and related fields.

4.16 Concerning the use of languages, the instructions to authors holds: 'Papers are to be written in simple, correct and concise French, German or English'. While a national scope and linguistic and disciplinary heterogeneity have been some of its constant features, the journal has nevertheless qualitatively changed over the years. As already noted, instructions to authors have been established in 2002. Concerning the review process it is stated:

Articles submitted for publication are reviewed by the editorial board and by one or two referees. The final decision on acceptance or rejection of the manuscript is taken by the editorial board. Manuscripts not prepared according to the following instructions to authors will be returned for correction prior to review.

4.17 The journal has become firmer - and more like international journals - concerning reviewing. The former editor of the journal explained:

Since it is called Ferrantia [...] we have become more strict and tell people to follow the instructions $[\ldots]$ In the beginning we had on purpose a style [...], a simplified procedure that allowed people to present the thing more naturalistically. Now we want to have a certain scientific standing (S3).

4.18 The journal has shifted from a more 'naturalistic' to a more 'scientific' style. It has, in fact, undergone a change that is noticeable for scientific articles in general in the 20th century - they have become more formalised and less personal and varied (Gross et al. 2002:118). Revealingly, the current chief editor explained, 'We try [...] mainly through reviewers and also through the criteria we have fixed, to keep [...] amateurism out a bit' (S5). 
4.19 Yet, this shift from amateurism towards a more scientific standing is not absolute. In the above quotes, terms like 'a bit' and 'a certain' reveal that the move towards professionalism is not total. According to the chief editor of the journal: 'Of course, we are not that severe [...] it is more important for us that it is scientifically correct and that the method is okay [...]. This means that we do want to raise the standard a bit, but we do not pretend to be the Journal of Biology ' (S5). Another member of the editorial board stressed, 'If we now set the bar very high - though it should be correct - but I think then we would perhaps scare young people and others' (S6).

4.20 The journal's quality is defined in relation to two positions. On the one hand, the scientific quality of the journal has allegedly risen and it is through a review system and through instructions to authors that publications should be 'scientifically correct'. On the other hand, the journal is 'not that severe', however. It does not aim to achieve the same standard as international journals. The journal's standing is, then, situated between a more 'amateuristic', naturalistic and 'less severe' standing, situated in the past, and a high international standing, mobilised as a means for comparison but not as a goal per se. This position has also been articulated in terms of intended audience. According to its former editor, the journal is 'not only for specialists, [but] also for naturalists or people interested in nature' (S3).

4.21 The review process of the journal is situated between two extremes: between double-blind anonymized review and very 'light' review (see Cronin 2001). Often collaborators already know who will referee their article beforehand and frequently they themselves select a referee of their own choice, for example a foreign scientist they collaborate with. Yet, even though editors claim to be 'not that severe' this does not mean that the review process is an easy task. Some staff members have argued that the reviewing process is a balancing act requiring Fingerspitzengefühl (literal translation: feeling on the fingertips; usual translation: tact and sensitivity) - often, also, because the manuscripts submitted by the collaborators are their 'lifework' and therefore difficult to reject. It seems that negotiating a space between amateurism and professionalism and between critically reviewing and not refusing collaborators' work straightaway is difficult. One could even argue that the Museum cannot refuse collaborators' contributions since publishing in the journal constitutes an important motivation for them. In a sense, even if the journal is reviewed and published by the Museum, it is foremost so for the collaborators. Thus, while refusing collaborators' contributions might perhaps be 'scientifically correct' it would be 'politically incorrect'.

4.22 The journal is not only a forum through which scientific knowledge is made and exchanged. The need for Fingerspitzengefühl reveals the social and political dimensions of the relationships played out. Staff members often mentioned that they had to put on 'gloves' to deal with some of the collaborators. The vocabulary used to describe this nursing and caring of the collaborators reveals the fragility of the connections that link them to the Museum. Since the connection is not permanent, nor strong, but rather partial and fragile it has therefore to be nurtured and cultivated with care (Meyer 2008). More so, the need for Fingerspitzengefühl indicates that this kind of relation cannot be rationalized, formalized, or institutionalized but that it has to be dealt with individually and specifically. To put it this way: the Museum cannot control - and use technical and 'cold' devices to discipline subjects - but has to care by fostering a 'warm' world of people (see Mol 2006, Mol 2008).

\section{Discussion}

5.1 As we have seen, the Museum puts some efforts into assuring that the 'wild bunch' of the collaborators delivers data, specimens and texts 'in resonance' with the Museum. There is a logic of exchange: the collaborators are nominated and they receive logistic and scientific support; and, in return, they provide the Museum with specimens and data. Yet, creating a centre, a homogeneous and disciplined place where the collaborators would have (at least some) things in common is a difficult task since their research interests and their socio-cultural backgrounds are very diverse. More so, since collaborators are situated on the periphery of the Museum, disciplining them, aligning their practices and interests and standardising their data is far from easy.

5.2 I now want to further delve on three issues that have come to the fore in the paper. First, the issue of naming. At the encounters examined in this paper, the names of the collaborators were clearly visible. They were inscribed on surfaces: on lists of participants who attend an event, as speakers on programs, on badges, as authors beneath the titles of publications, and so on. Their names appeared intimately linked to them being a scientific collaborator. Since the 'process of naming also sets in place the concept of borders to a community' (Molyneux-Hodgson and Facer 2003:156), naming the scientific collaborator means, then, delimiting the community of collaborators. By designating scientific collaborators as such, the Museum creates an ordered, homogeneous space of commonalities (see Hetherington 1997:191). This is one level through which the Museum manages heterogeneity: by producing an enclosed discursive space by simply naming some people scientific collaborators of the Museum.

5.3 Second, as we have seen, collaborators can choose. They can write and talk about topics within a 
range of disciplines and they can do so in various languages. The content and the format of the conference presentations leave some room of manoeuvre and the review process of the journal is 'not that severe'. Both these forums are not very restrictive. Compared to conventional meetings and journals, they appear less professional, or at least very different. In 'professional' places of encounter mostly one language is used English being the lingua franca of international science (Garfield 1989) - and there is a stronger focus on specific disciplines, themes, or domains. However, the places of encounter between the Museum staff and the collaborators are less rigid and allow more freedom. Including amateurs in the co-production of scientific knowledge necessitates the inclusion of flexibilities, that is, the exclusion of rigid frames.

5.4 Third, we have also seen evidence of symbolic gift-exchange. Not only was there an exchange of scientific knowledge, but we saw that things of a more symbolic order were also exchanged. At the bodily encounters food and drinks were provided and thanks were expressed. The textual encounters are, we can argue, places where the collaborators gain visibility, recognition and prestige. These are places where the Museum is giving; where an exchange with a relational dimension is performed with an intention to maintain and develop the relationship with the collaborators. On the other side, the collaborators are also giving, their presence and their activities at these encounters are rendered possible through volunteering, in other words, through 'the gift of time' (Prouteau and Wolff 2004).

5.5 I would argue that it is the combination of these elements - practices of naming, assuring linguistic heterogeneity and thematic flexibility, and providing a space for various kinds of knowledge and symbolic gift-exchange - that enables the museum to keep the 'wild bunch' of the amateurs somehow together. Importantly, this assemblage is provided for through various encounters that are not only important for enabling knowledge to be exchanged but also for nurturing certain kinds of connectivities. They are important for the maintenance of 'weak ties' (Granovetter 1973). It is precisely those loose attachments that seem to get cultivated through boundary encounters. The encounters discussed in this paper are not places where an already fixed and coherent community assembles. Rather, these are places where we encounter the 'collective' which is 'not a thing in the world, a being with fixed and definitive borders, but a movement of establishing provisional cohesion that will have to be started all over again every single day' (Latour 2004:147). Hence, beyond their role as 'community-making devices', they are also devices that nurture weak ties. They are devices that care for the weak ties that exist between amateurs and professionals. The 'texture' of such caretaking can be defined as follows:

Care is a process: it does not have clear boundaries. It is open-ended [...] a matter of various hands working together (over time) towards a result. Care is not a transaction in which something is exchanged [...] but an interaction in which the action goes back and forth (in an ongoing process) (Mol 2008:18).

As a process with indistinct boundaries that moves in-between amateurs and professionals, this logic of care seems to have the right 'texture' to help making a heterogeneous, unbound, and partially connected group of people produce knowledge together. In doing so, it brings about not an epistemic community but rather an 'epistemic collective', that is, a rather fragile collective that is only ever temporarily and partially stabilised around devices and events that produce and publicise knowledge. ${ }^{[5]}$

5.6 As much as museum professionals need to care for weak ties, sociologists need to account for them in a more detailed manner. In sociology, the ties that hold people together are too often treated as being equal and their variability is often being overlooked. But people can be differently connected. Responses to enrolment are varied along a rich continuum, including partial signings-on and partial commitments (Star 1991:49-50). There are, to say the least, weak and strong connections. The picture is even more complex as between strong and weak ties there are potentially all kinds of ties. This reminds us of a criticism made a long time ago by Dennis Wrong, who argued that 'All men are socialized [...] but this does not mean that they have been completely moulded by the particular norms and values of their culture' (Wrong 1961:192). As much as Wrong criticised the 'oversocialized conception' of humans by sociologists, we must remediate to the current trend in the social studies of science to present an 'overnetworked conception' of those who produce scientific knowledge. Amateurs are but one example of people who are partially connected, who are loosely tied to scientific communities. They escape efforts of governing, professionalizing, and coordinating scientific research. Strong ties - contracts, deadlines, money, assessments, strict rules, etc. - do not work within amateurs' knowledge economy. To be able to tame a 'wild bunch' of amateurs it is necessary for professionals to care for weak ties and to use rather delicate methods. The role that natural history museums can play here is an issue that needs to be further explored in future studies.

\section{Acknowledgements}

This article is based on my PhD; I thank Sharon Macdonald and Susan Molyneux-Hodgson for having been 
such professional and witty supervisors. Thanks to Dave Phillips for our discussions about weak ties, Liliana Doganova for proofreading the article, and three anonymous referees for their comments. Thanks also to the Luxembourg Museum of Natural History for having allowed me to do my fieldwork and to the Luxembourg Ministry of Research for having funded my study.

\section{Notes}

${ }^{1}$ I thank Susan Molyneux-Hodgson for having alerted me to these points.

${ }^{2}$ Several questions do need further scrutiny (and haven't been examined in the project upon which this paper is based). Do amateurs sometimes have less freedom, in terms of their knowledge claims being taken less seriously, and them having less academic freedom than their professional 'peers'? And, despite their freedom, are amateurs sometimes, because of their status, actually easier to control and manage than professionals?

${ }^{3} \mathrm{~A}$ third boundary encounter, databases, has been examined elsewhere (Meyer 2009).

${ }^{4}$ No staff member gave a talk at the meeting - which is usually the case at these meetings.

5 While the term 'epistemic collective' has been used in economic geography (see i.e. Grabher 2004), my definition here is more sociological and aims to stress the work, difficulties and Fingerspitzengefühl involved in bringing together such a collective.

\section{References}

ALBERTI, S. (2001) 'Amateurs and Professionals in One County: Biology and Natural History in Late Victorian Yorkshire', Journal of the History of Biology , Vol. 34, No. 1, pp. 115-147. [doi:10.1023/A:1010373912743]

ASMA, S. T. (2001) Stuffed Animals And Pickled Heads: The Culture And Evolution Of Natural History Museums. Oxford: Oxford University Press.

BERGQUIST, M. and LJUNGBERG, J. (2001) 'The power of gifts: organizing social relationships in open source communities', Information Systems Journal, Vol. 11, No. 4, pp. 305-320. [doi:10.1046/j.13652575.2001.00111.x]

BOWKER, G. C. (2000) 'Biodiversity Datadiversity', Social Studies of Science, Vol. 30, No. 5, pp. 643-683. [doi:10.1177/030631200030005001]

CALLON, M. (1998a) 'Les différentes formes de démocratie technique', Annales des Mines, Janvier 1998, pp. 63-73.

CALLON, M., LASCOUMES, P. and BARTHE, Y. (2001) Agir dans un monde incertain. Essai sur la démocratie technique. Paris: Seuil.

CALLON, M. and RIP, A. (1992) 'Humains, non-humains: morale d'une coexistence', in J. Theys and B. Kalaora (editors) La Terre Outragée. Les Experts sont Formels!, Paris: Ed. Autrement, pp. 140-156.

CORLETT, W. (1989) Community Without Unity: A Politics of Derridian Extravagance. Durham: Duke University Press.

CRONIN, B. (2001) 'Hyperauthorship: A postmodern perversion or evidence of a structural shift in scholarly communication practices?', Journal of the American Society for Information Science and Technology , Vol. 52, No. 7, pp. 558-569. [doi:10.1002/asi.1097.abs]

DROUIN, J. M. and BENSAUDE-VINCENT, B. (1996) 'Nature for the People', in N. Jardine, J. A. Secord and E. C. Spary (editors) Cultures of Natural History, Cambridge: Cambridge University Press, pp. 408 -425 .

ELLIS, R. and WATERTON, C. (2004) '“Amateurs as Experts": observing the emergence of a new biodiversity collective', paper presented at the 4S\&EASST conference 'Public Proofs. Science, technology and democracy', Ecole des Mines de Paris, 25-28th of August 2004.

EPSTEIN, S. (1995) 'The Construction of Lay Expertise: AIDS Activism and the Forging of Credibility in the 
Reform of Clinical Trials', Science, Technology and Human Values, Vol. 20, No. 4, pp. 408-437. [doi:10.1177/016224399502000402]

FINDLEN, P. (1994) Possessing nature: museums, collecting, and scientific culture in early modern Italy . Berkeley, London: University of California Press.

FOURNIER, V. (1999) 'The Appeal to "Professionalism" as a Disciplinary Mechanism', The Sociological Review, Vol. 47, No. 2, pp. 280-307. [doi:10.1111/1467-954X00173]

GARFIELD, E. (1989) 'The English Language: The Lingua Franca Of International Science', The Scientist, May 15.

GARVEY, W. D. and GRIFFITH, B. C. (1972) 'Communication and Information Processing within Scientific Disciplines: Empirical Findings for Psychology', Information Storage and Retrieval, Vol. 8, No. 3, pp. 123 -136. [doi:10.1016/0020-0271(72)90041-1]

GIANNONI, D. S. (2002) 'Worlds of gratitude: A contrastive study of acknowledgement texts in English and Italian research articles', Applied Linguistics, Vol. 23, Part 1, pp. 1-31. [doi:10.1093/applin/23.1.1]

GIERYN, T. F. (1983) 'Boundary-work and the demarcation of science from non-science. Strains and interests in professional ideologies of scientists', American Sociological Review, Vol. 48, No. 6, pp. 781 -795. [doi:10.2307/2095325]

GIERYN, T. F. (1995) 'Boundaries of Science', in S. Jasanoff, G. E. Markle, J. C. Peterson, and T. Pinch (editors) Handbook of Science and Technology Studies, Thousand Oaks: Sage, pp. 393-443.

GRABHER, G. (2004) 'Temporary Architectures of Learning: Knowledge Governance in Project Ecologies', Organization Studies, Vol. 25, No. 9, pp. 1491-1514. [doi:10.1177/0170840604047996]

GRANOVETTER, M. S. (1973) 'The Strength of Weak Ties', American Journal of Sociology, Vol. 78, No. 6, pp. 1360-1380. [doi:10.1086/225469]

GROSS, A. G., HARMON, J. E. and REIDY, M. (2002) Communicating science: the scientific article from the 17th century to the present. Oxford: Oxford University Press.

HAGSTROM, W. (1982) 'Gift giving as an organizing principle in science', in B. Barnes and D. Edge (editors) Science in Context: Readings in the Sociology of Science, Cambridge: MIT Press, pp. 21-34.

HEIN, H. S. (2000) The museum in transition: a philosophical perspective. Washington: Smithsonian Institution Press.

HETHERINGTON, K. (1997) 'In Place of Geometry: the Materiality of Place', in K. Hetherington and R. Munro (editors) (1997) Ideas of Difference: Social Spaces and the Labour of Division , Oxford: Blackwell, pp. 183-199.

HOOPER-GREENHILL, E. (2000) 'Communication and Communities: Changing Paradigms in Museum Pedagogy', in S. Lindqvist (editor) Museums of Modern Science, USA: Science History Publications, pp. 179-188.

KEITH, W. (1997) 'Science and Communication: Beyond Form and Content', in J. H. Collier and D. M. Toomey (editors) Scientific and Technical Communication. Theory, Practice and Policy, Thousand Oaks: Sage, pp. 299-326.

KNORR-CETINA, K. (1999) Epistemic cultures: how the sciences make knowledge. Cambridge: Harvard University Press.

KUKLICK, H. (1997) 'After Ishmael: The Fieldwork Tradition and Its Future', in A. Gupta and J. Ferguson (editors) Anthropological Locations: Boundaries and Grounds of a Field Science , Berkeley: University of California Press, pp. 47-65.

LAMB, R. and DAVIDSON, E. (2005) 'Information and Communication Technology Challenges to Scientific Professional Identity', The Information Society, Vol. 21, No. 1, pp. 1-24. [doi:10.1080/01972240590895883]

LANKFORD, J. (1981) 'Amateurs and Astrophysics: A Neglected Aspect in the Development of a Scientific Specialty', Social Studies of Science, Vol. 11, No. 3, pp. 275-303. [doi:10.1177/030631278101100301]

LATOUR, B. (1987) Science in action. How to Follow Scientists and Engineers through Society . 
Cambridge: Harvard University Press.

LATOUR, B. (2004) Politics of nature: how to bring the sciences into democracy . Cambridge: Harvard University Press.

LAVE, J. and WENGER, E. (1991) Situated learning: legitimate peripheral participation . Cambridge: Cambridge University Press.

LEWIS, J. D. and WEIGART, A. J. (1990) 'The Structures and Meanings of Social-time', in J. Hassard (editor) The Sociology of Time, Basingstoke: Macmillan, pp. 77-101.

MAUSS, M. (1990) The gift: the form and reason for exchange in archaic societies . London: Routledge.

MEYER, M. (2005) 'Partial Scientists - Boundaries and Spaces in Museums of Natural History', Sheffield Online Papers in Social Research, 8, pp. 1-18.

MEYER, M. (2006) Partially connected to science: the Luxembourg Museum of Natural History and its scientific collaborators. PhD thesis, Sheffield: University of Sheffield.

MEYER, M. (2008) 'On the boundaries and partial connections between amateurs and professionals', Museum and Society, Vol. 6, No. 1, pp. 38-53.

MEYER, M. (2009) 'Objet-frontière ou Projet-frontière? Construction, (non-)utilisation et politique d'une banque de données', Revue d'Anthropologie des Connaissances (special issue: Revisiting the 'boundary object'), Vol. 3, No. 1, pp. 127-148.

MOL, A. M. (2006) 'Handle with Care. Fragile. Human Flesh', paper given at the EASST conference Reviewing Humanness: Bodies, Technologies and Spaces, University of Lausanne, Switzerland, 23-26 August 2006.

MOL, A. M. (2008) The Logic of Care: Health and the Problem of Patient Choice . London: Routledge.

MOLYNEUX-HODGSON, S. and FACER, K. (2003) 'The textbook as cultural artefact: reproducing the culture of science', in R. Sutherland, G. Claxton, and A. Pollard (editors) Learning and Teaching: Where Worldviews Meet, Stoke: Trentham, pp. 153-74.

MOLYNEUX-HODGSON, S. and MEYER, M. (2009) 'Tales of emergence - synthetic biology as a scientific community in the making', BioSocieties, Vol. 4, No. 2/3, pp. 129-145 [doi:10.1017/S1745855209990019]

O'CONNOR, J. G. and MEADOWS, A. J. (1976) 'Specialization and Professionalization in British Geology', Social Studies of Science, Vol. 6, No. 1, pp. 77-89. [doi:10.1177/030631277600600104]

PICKSTONE, J. (2000) Ways of Knowing. A New History of Science, Technology and Medicine . Manchester: Manchester University Press.

PROUTEAU, L. and WOLFF, F. C. (2004) 'Donner son temps: les bénévoles dans la vie associative', Économie et Statistique, No. 372, pp. 3-39. [doi:10.3406/estat.2004.7264]

SHAPIN, S. (1988) 'The House of Experiment in Seventeenth Century England', ISIS, 79, pp. 373-404. [doi:10.1086/354773]

SHAPIN, S. (1994) A Social History of Truth: Civility and Science in Seventeenth-Century England, Chicago: Chicago University Press.

SHAPIN, S. and SCHAFFER, S. (1985) Leviathan and the air-pump: Hobbes, Boyle, and the experimental life, Princeton: Princeton University Press.

STAR, S. L. (1991) 'Power, Technologies and the Phenomenology of Standards: On Being Allergic to Onions', in J. Law (editor) A Sociology of Monsters: Essays on Power, Technology and Domination , London: Routledge, pp. 26-56.

STAR, S. L. and GRIESEMER, J. R. (1989) 'Institutional ecology, "translations" and boundary objects: Amateurs and professionals in Berkeley's museum of vertebrate zoology, 1907-39', Social Studies of Science, Vol. 19, No. 3, pp. 387-420. [doi:10.1177/030631289019003001]

STEBBINS, R. A. (1977) 'The Amateur: Two Sociological Definitions', The Pacific Sociological Review, Vol. 20, No. 4, pp. 582-606. 
STEBBINS, R. A. (1992) Amateurs, professionals, and serious leisure. Montreal, London: McGill-Queen's University Press.

STEBBINS, R. A. (2004) Between Work and Leisure: A Study of the Common Ground of Two Separate Worlds. New Brunswick: Transaction Publisher.

STRATHERN, M. (1991) Partial connections. Savage: Rowman \& Littlefield.

TAYLOR, B. (1995) 'Amateurs, Professionals and the Knowledge of Archaeology', The British Journal of Sociology, Vol. 46, No. 3, pp. 499-508. [doi:10.2307/591853]

WENGER, E. (1998) Communities of practice: learning, meaning, and identity . Cambridge: Cambridge University Press.

WENGER, E. (2000) 'Communities of Practice and Social Learning Systems', Organization, Vol. 7, No. 2, pp. 225-246. [doi:10.1177/135050840072002]

WRONG, D. H. (1961) 'The oversocialized conception of man in modern sociology', American Sociological Review, Vol. 26, No. 2, pp. 183-193. [doi:10.2307/2089854] 